\title{
Mapping The European Digital Accessibility Field: The IMPACT Project
}

\author{
Estella, Eo, Oncins \\ DITEO, Universitat Autònoma de \\ Barcelona, Spain
}

\author{
Altinier, Aa, Armony \\ KOENA, France
}

\author{
Donal, Df, Fitzpatrick \\ School of Computing Dublin City \\ University, Ireland
}

\begin{abstract}
New advances in Information and Communication Technologies (ICT) have generated a convergent media environment towards the web. Digital media is ubiquitous and sometimes we might not realise how now much it affects our daily lives, as it is being used to communicate, entertain, learn, and almost all other activities. At present, most digital content is still not accessible for all. The requirement for digital accessibility when accessing ICT products has increased since the endorsement of the Convention on the Rights of Persons with Disabilities (UNCRPD) by European Directives.

This article will first present an overview of the current state of digital accessibility legal framework in Europe. This will enable a better understanding of the existing gaps in the market and the training needs in the digital accessibility field. The methodology followed in the first stage of the IMPACT project will then be presented. Firstly, an analysis of the existing training in the digital accessibility field was conducted, which was used as the basis to create a first draft of the competences and skills that a digital accessibility professional should acquire and master. Secondly, an online survey to assess the defined competences and map the current status of digital accessibility in Europe was conducted. Results obtained will be discussed and further steps in the project which involve the design of a modular curriculum and the certification process will be outlined.
\end{abstract}

\section{CCS CONCEPTS}

- Human Computer Interaction (HCI); • Accessibility; • User characteristics;

\section{KEYWORDS}

Digital accessibility training, Digital accessibility skills, EN301549

\section{ACM Reference Format:}

Estella, Eo, Oncins, Altinier, Aa, Armony, and Donal, Df, Fitzpatrick. 2020. Mapping The European Digital Accessibility Field: The IMPACT Project. In 9th International Conference on Software Development and Technologies for Enhancing Accessibility and Fighting Info-exclusion (DSAI 2020), December 02-04, 2020, Online, Portugal. ACM, New York, NY, USA, 5 pages. https: //doi.org/10.1145/3439231.3440608

Permission to make digital or hard copies of all or part of this work for personal or classroom use is granted without fee provided that copies are not made or distributed for profit or commercial advantage and that copies bear this notice and the full citation on the first page. Copyrights for components of this work owned by others than ACM must be honored. Abstracting with credit is permitted. To copy otherwise, or republish, to post on servers or to redistribute to lists, requires prior specific permission and/or a fee. Request permissions from permissions@acm.org.

DSAI 2020, December 02-04, 2020, Online, Portugal

(C) 2020 Association for Computing Machinery.

ACM ISBN 978-1-4503-8937-2/20/12 . \$ \$15.00

https://doi.org/10.1145/3439231.3440608

\section{INTRODUCTION}

In 2019, the European Accessibility Act (2019/882) was approved, which along the Web Accessibility Directive (2016/2102) and the reviewed Audiovisual Media Service Directive 2018/1808), offers the legal context for accessibility in Europe in the next decade. a Harmonised European Standard is now in place with the ratification of EN 301549. On the one hand we have a demonstrably ambitious legislation towards Human Rights compliance in Europe and, on the other hand, we have an ever-evolving digital landscape which must become accessible to fulfil EN301549. In addition, accessibility has now gone beyond its boundaries to include not only those who live with disabilities. In Europe secure media access and comprehension for all its citizens across social, cultural and language groups have become a key requirement in the Digital Single Market (DSM).

According to the report from the EC $(2009)^{1}$ levels of full compliance with existing web accessibility guidelines remain very low, and the situation across the EU appears to be a considerable distance from achieving targets that were defined in the Riga Declaration as goals for 2010. In a survey carried out by the European Disability Forum (EDF) in 2019 on "Web Accessibility Directive transposition and implementation" 2 , it was reported that while organisations representing persons with disabilities were involved in the transposition of the Web Accessibility Directive, $42 \%$ were not (very) satisfied with the result. In terms of implementation the majority of new websites $(80 \%)$ were found not accessible. In addition, current research studies (Máñez-Carvajal \& Fernández-Piqueras, 2019; Pribeanu, 2019) stress that web sites present barriers of access to information and that these barriers are even greater in the case of those who make use of assistive technology. Whilst the majority of access barriers are found in the existing ICT products and services, many new ICT products, services and tools are further produced with less than satisfactory access for all users. Statistics provided by the EC $(2018)^{3}$ report significant percentages of the population with accessibility needs (e.g. around 80M people in Europe), of an aging demographic (with a direct implication on accessibility needs), and also of newcomers, refugees, and displaced people, and those who have learning or hidden disabilities. The way in which media is consumed also affects accessibility with around $85 \%$ of people with no hearing loss consuming content on social media with subtitles in public spaces.

\footnotetext{
${ }^{1}$ Retrieved November 21, 2020 from https://ec.europa.eu/digital-singlemarket/en/news/study-report-web-accessibility-european-countries-levelcompliance-latest-international

${ }^{2}$ Retrieved November 21, 2020 from https://ec.europa.eu/digital-single-market/en/ news/sixth-meeting-web-accessibility-expert-group

${ }^{3}$ Retrieved November 10, 2020 from https://ec.europa.eu/sport/news/2018/new-studyaddresses-access-sport-people-disabilities_en
} 
In a recent survey carried out by Deque Systems (2020) entitled "How is COVID-19 Impacting Digital Accessibility?"4 most companies and organisations rated their accessibility expertise as elementary and many marketers were unaware of their role in digital accessibility compliance, such as adding alt text to images on social media. In addition, companies and organisations highlighted training in the digital accessibility field as one of their main challenges. Furthermore, in a decision of the European Ombudsman (Strategic Survey OI / June 2017, 6/2017/EA) ${ }^{5}$ on how the European Commission ensures that people with disabilities can access its websites from December 2018, there is a need for Mandatory accessibility training for all staff working on websites. Hence the creation of the IMPACT project, which stands for Inclusive Method based on Perception of Accessibility and Compliance Testing. It is a strategic partnership bringing together parties from different fields dealing with innovation in higher education, with the main aim of designing, testing and certifying a modular curriculum in digital accessibility for vocational and academic training that meets the needs of the labor market and society.

In terms of structure the IMPACT project follows the path of previous educational projects such as ACT (Matamala and Orero 2019), ADLAB and ADLAB PRO (Perego 2017) and existing ones such as LTA (Oncins et al. 2019). All these ERASMUS+ projects have been granted and developed to train new professionals in the media accessibility field in different roles. While these projects have a main focus on the services to ensure that media accessibility content is accessible, there was a need to scale accessibility at a transversal level, that of ICT accessibility with a more innovative understanding of new media and disability issues (Goggin and Newell 2003). This departure from the disability and accessibility towards usability and diversity points to normalisation (Ellis 2016, Taylor 2017, Orero and Tor-Carrogio 2018, Agulló et al 2019) . To fill this gap the new ERASMUS+ project IMPACT aims at defining the competences and skills that an ICT accessibility professional should acquire and master.

\section{METHODOLOGY}

The IMPACT project aims at covering the gap of the above mentioned lack of training and awareness in the market through a modular curriculum and online open resource materials, providing the required competences and skills for academic and vocational stakeholders in the digital accessibility field. The first step towards identifying the necessary core knowledge was to review existing training courses on digital accessibility in order to create a first draft of the skills, and design an online survey to assess the proposed competences. The results obtained would deliver the basis for the design of a competence-based modular curriculum which is the next stage of the project.

An overview of the available training in digital accessibility shows that existing offerings is divided between academic and vocational education. The first is usually carried out at universities, as part of a technological degree and mainly centered on providing low effort solutions that allow compliance with the law (Ferati 2020).

\footnotetext{
${ }^{4}$ Retrieved September 14, 2020 from https://cdn2.hubspot.net/hubfs/153358/Deque COVID-19-Report.pdf

${ }^{5}$ Retrieved September 14, 2020 from https://www.ombudsman.europa.eu/en/case/en/ 50299
}

The latter is primarily provided by private companies or organisations in the form of task-oriented vocational courses that last a short period of time. In both cases training is focused on compliance with existing digital accessibility legislation and standards, such as WCAG2.0/2.1. Existing training fails to provide more inclusive and empathy-driven design, implementation and testing approaches, as technology cannot be isolated from the social context (Ferati 2020; Foley and Ferri 2012; Lazar 2002; Putnam et al. 2016; Seale 2004). This generates a lack of competence in understanding accessibility with social inclusion in mind, especially in the case of the technology community, which could benefit from shifting its attention from the product of accessibility towards the process of accessibility (Seale 2004).

The IMPACT project aims at developing the skills and designing the curriculum for one single profile: that of "Digital Accessibility Educator". This professional may be in charge of understanding, detecting, planning, implementing and promoting digital accessibility in different digital contexts. A first draft of the competences has been validated through an online survey.

\subsection{Questionnaire design}

As a result of this first evaluation stage a general survey designed by IMPACT partners was created in English, and translated into the four other languages of the partners in the consortium, namely Catalan, French, German and Spanish. It was then sent to different stakeholders in the digital accessibility field. The objective of the survey was to map the digital accessibility practices and training currently available mainly in Europe. The specific issues examined include the following:

(1) Please choose your age (2) In which country do you work? (2b) In which town/city do you work? (3) Digital accessibility means that websites, tools, and technologies are designed and developed so that people with disabilities can use them. More specifically, people can perceive, understand, navigate, interact and contribute to digital content. How well are you familiar with the concept of 'digital accessibility'? ${ }^{6}$ Please indicate it on the 5- point scale. (4) How do you relate to digital accessibility (multiple answers possible), (5) How important is it to provide digital accessibility in your opinion? Please indicate it on the 5-point scale, (6) Is your own, or your organisation's website accessible? (7) Has your or your organisation's website been audited according to any accessibility standard? (8) How long have you been working in digital accessibility? (9) What is your professional situation? (10) Are you working for a private or a public organisation? (11) What is the highest level of education, which you have completed? (12) How familiar are you with the following legislation and standards? Please indicate it on the 5-point scale (13) Are you aware of any other national or international legislation or standard about digital accessibility? If yes, which one? (14) Do you think that there is a need for training in digital accessibility? (15) How important do you consider the following skills in digital training? (16) Would you like to add

\footnotetext{
${ }^{6}$ The definition provided was 'Digital accessibility means that websites, tools, and technologies are designed and developed so that people with disabilities can use them. More specifically, people can perceive, understand, navigate, interact and contribute to digital content'. This text departs from the W3C definition for 'web accessibility', the term 'web' was replaced with the term 'digital' allowing a broader inclusion of the different digital contexts that will be dealt in the coming stages of the IMPACT project, in particular the curriculum definition.
} 
any new competence that you consider important and is currently missing in accessibility digital training?

The questionnaire was designed to take approximately ten minutes to complete, with a majority of closed-ended items requiring the ticking of boxes to allow quick and easy feedback, some questions requiring graded responses using a variation on the Likert scale technique which replaced the standard set of responses (very important to not important at all or very familiar to not familiar at all) with a numerical 1-5 scale and a few open-ended questions for further details. Moreover, in order to gather further qualitative data to complement the quantitative data collected, most questions included an open-ended item in the form of room for comments.

\subsection{Data collection}

A total of 198 stakeholders from Europe, Asia-Pacific and the United States of America provided input. From which 71 were private organisations, 101 were public organisations, 15 were end users and 11 were persons under "Other" profiles, mainly students. In terms of profile 57 were digital accessibility service providers, 55 were digital accessibility training providers and 51 were users interested in digital accessibility training.

Whilst the same data collection method was used across the partner countries (i.e. on-line questionnaires in the five languages of the consortium), there were some variances in quantities. Therefore, scaling is used in the comparative analysis across the different language versions. In each case the variance between the results from the different language versions is analysed.

\section{SURVEY RESULTS}

The data collected provides a mapping of digital accessibility current practices and training across different countries. The collected quantitative and qualitative data offers the opportunity for further in-depth analysis of the findings for additional insights which will be provided in the next sections.

\subsection{Demographic data}

On average the main age range of the respondents was between 25 - 34 years old. In all language versions, participants reporting 0-2 years experience were aged between 25-34 years old. On the other hand, in the English version, $46,6 \%$ of the participants reported more than ten years of experience in the digital accessibility field. Therefore, the main age ranges selected in the English version were first between 55-64 years old, and between 35-44 years old and 45-54 years old received the same number of responses.

In terms of geography, answers were received mainly from the following countries: Austria, France, Ireland, Spain, Germany and UK, but also from other European countries such as, Belgium, Denmark, Italy, Luxembourg, Netherlands, Norway and Poland. Answers were also received from countries outside the EU, such as Australia, Canada, India and United States. In terms of cities and towns, most respondents reported to live mainly in urban areas. Regarding the professional situation and type of organisation, on average most digital accessibility professionals were employees $(73,56 \%)$ working for a public organisation $(67 \%)$. This might be due to the fact that public organisations were the first to adopt digital accessibility under legal obligation. Participants reported also to work for other organisations, such as: charity.

Regarding the level of education on average $42 \%$ of the participants had completed a postgraduate degree, $26 \%$ of the participants had completed an undergraduate degree and $18 \%$ of the participants had completed a $\mathrm{PhD}$.

The participation of end-users with different (dis)abilities was crucial in order to understand their needs, and also to consider their opinion about the proposed competences in the digital accessibility training field.

\subsection{Importance of digital accessibility}

In all versions participants reported to be very familiar (66\%) in the first place, familiar (17\%) in the second place and somewhat familiar $(14 \%)$ with the term 'digital accessibility'. Regarding the relationship of participants with digital accessibility it was possible to select more than one option. The most selected one with $52,94 \%$ was 'I use digital accessibility in my professional practices'. Most participants selecting this option also selected 'I manage digital accessibility in my organisation' $(34,7 \%)$ and 'I work for an organisation with a digital accessibility policy' $(29,34 \%)$. A second combination was with 'I am a provider of digital accessibility services' $(31,26 \%)$ and 'I am a provider of digital accessibility courses' (24,56\%).

\subsection{Accessibility practices at organisations}

On average $45 \%$ reported that their website or the website of their organisation is accessible. $22 \%$ reported that their website is partially accessible or that measures for improving accessibility were being carried out. On the other hand, $21 \%$ reported that their website was not accessible and $12 \%$ did not know. Regarding the question: "Has your own organization website been audited according to any accessibility standard?", $55 \%$ of the participants reported that it was, $26 \%$ of the participants responded positively, $26 \%$ responded negatively and $19 \%$ did not know.

\subsection{Digital accessibility legislation}

In terms of familiarity with current legislation and standards in the digital accessibility field, WCAG2.0/2.1 is by far the most known standard among professionals in the accessibility field $16.5 \%$ of the participants reported not to be familiar at all, $10 \%$ reported to be not familiar, $16.5 \%$ were somewhat familiar, $25.5 \%$ were familiar and $31.5 \%$ were very familiar with the standard. Regarding the EU Web Accessibility Directive, $8.5 \%$ reported to be not familiar at all, $18.5 \%$ were not familiar, $35.5 \%$ were somewhat familiar, $18 \%$ were familiar and $19.5 \%$ were very familiar. Regarding the standard EN 301549, $28.5 \%$ of the participants reported to be not familiar at all, $29.5 \%$ were not familiar, $23.5 \%$ were somewhat familiar, $12 \%$ were familiar and $6.5 \%$ were very familiar. As it can be observed in image 1, a large number of professionals in the digital accessibility field are familiar with the WCAG and the EU Web Accessibility Directive. On the contrary, the standard EN 301549 remains largely unknown to most accessibility professionals. This accessibility European harmonised standard covers all ICT products, services and tools. It includes technical requirements and it also covers the web and other digital documents. 


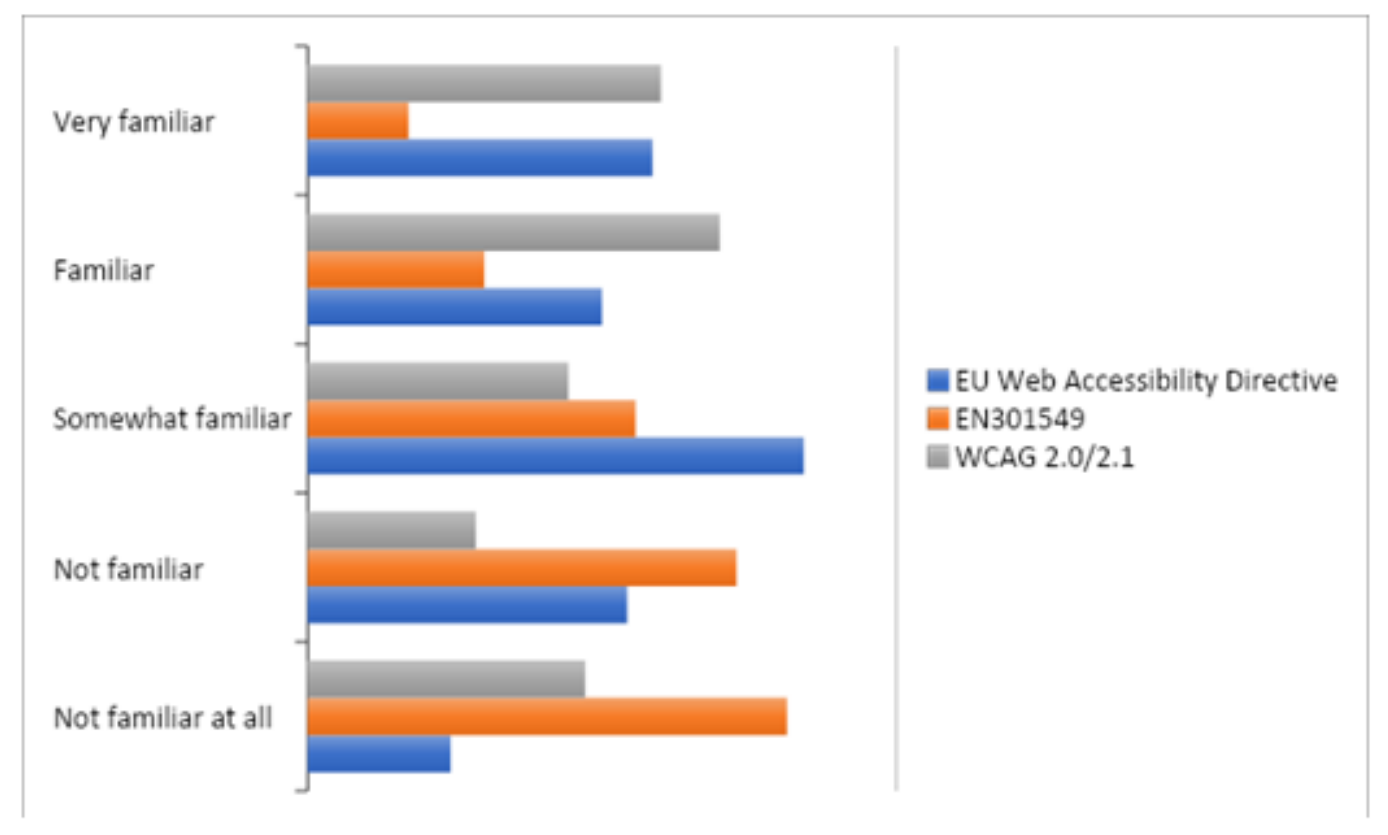

Figure 1: Familiarity with accessibility standards

\subsection{Digital accessibility training}

Regarding the need for training in digital accessibility $90,88 \%$ of the participants responded positively, 8,58\% of the participants didn't know and only $0,54 \%$ of the participants responded negatively. A close look at the importance of the four proposed competences: 1) Understanding digital accessibility, 2) Digital Accessibility context and digital accessibility services, 3) Implementing Digital accessibility and 4) Digital accessibility promotion, all competences were reported as very important or important. The competence with the highest score was 'implementing digital accessibility', followed by 'understanding digital accessibility' and 'digital accessibility promotion', and finally 'digital accessibility context and digital accessibility services'.

Regarding new competences that emerged from comments provided by participants most of them are already included in the four competences defined in question 15. Most of the comments referred mainly to the competence areas: 'Understanding digital accessibility', which deals with end users and 'Implementing digital accessibility', which deals with design for all principles.

It is important to highlight that 93 participants were interested in getting involved in a more specific survey on digital accessibility training, which confirms that there is an existing interest in digital accessibility training.

\section{CONCLUSIONS}

The findings discussed in this article contribute to the IMPACT project's global objective of establishing the professional profile and training for a 'Digital Accessibility Educator'. It provides, an overview of the current context of digital accessibility from the perspectives of professionals related to digital accessibility across different countries, identifying gaps and good practices. These findings feed directly into the subsequent stages of the project including the design of a modular curriculum, the definition and assessment of skills required of a digital accessibility educator and the final certification process.

The results from the survey reiterate the problem of training amongst organisations implementing accessibility policies and services mainly due to the lack of skills from an empathy driven perspective with social inclusion in mind. The findings suggest that at present digital accessibility training is needed especially in the case of the European standard EN301 549. While most participants are familiar or very familiar with the current legislation, the European standard EN301 549 remains unknown, even if it helps organisations to implement the European Web Accessibility Directive and includes WCAG2.0/2.1.

Furthermore, the results confirm the existing interest and clear demand for training in digital accessibility in all countries In short, there is a market for the training being developed as part of subsequent stages of the IMPACT project.

\section{ACKNOWLEDGMENTS}

This work has been partially funded by ERASMUS+ LTA 20181-DE01-KA203-004218, ERASMUS+ EASIT 2018-1- ES01-KA20305275, ERASMUS+ IMPACT 2019-1-FR01- KA204-062381, RAD PGC2018-096566-B-I00 and 2017SGR113.

\section{REFERENCES}

[1] Agulló, B., Matamala, A. and Orero, P. 2018. From Disabilities to Capabilities: testing subtitles in immersive environments with end users. HIKMA 17, 195-220.

[2] Convention on the Rights of Persons with Disabilities (CRPD). 2006. Retrieved September 14, 2020 from: https://www.un.org/development/desa/disabilities/ convention-on-the-rights-of-persons-with-disabilities/convention-on-therights-of-persons-with-disabilities- 2 .html 
[3] European Commission (EC). 2019. European Accessibility Act. Retrieved September 14, 2020 from: https://eur-lex.europa.eu/legal-content/EN/TXT/PDF/?uri= CELEX:32019L0882\&from=ES

[4] European Commission (EC). 2018. Mapping on access to sport for people with disabilities. Retrieved November 10, 2020 from: https://eur-lex.europa.eu/legalcontent/EN/TXT/PDF/?uri=CELEX:32019L0882\&from=ES

[5] European Commission (EC). 2018. Audiovisual Media Services Directive (AVMSD) Retrieved September 14, 2020 from: https://eur-lex.europa.eu/legal-content/EN/ TXT/?uri=LEGISSUM\%3Aam0005

[6] European Commission (EC). 2018. Digital Single Market: updated audiovisual rules. Retrieved September 14, 2020 from: http://europa.eu/rapid/press-release MEMO-18-4093_en.htm

[7] European Commission (EC). 2012. European Union Regulation 1025/ 2012 on European Standardization. Retrieved September 14, 2020 from: https://eur-lex. europa.eu/legal-content/EN/TXT/?uri=celex\%3A32012R1025

[8] European Commission (EC). 2009. Study report: Web accessibility in European countries: levels of compliance with latest international accessibility specifications, notably WCAG 2.0, and approaches or plans to implement those specifications. Retrieved November 9, 2020 from: https://ec.europa.eu/digital-single-market/en/news/study-report-webaccessibility-european-countries-level-compliance-latest-international

[9] Ellis, G. 2016. Impairment and Disability: Challenging Concepts of "Normality". In: A. Matamala and P. Orero (Eds.), Researching Audio Description. London: Palgrave Macmillan, 35-45.

[10] Ferati, M., \& Vogel, B. 2020. Accessibility in Web Development Courses: A Case Study. Informatics, 7, 8.

[11] Foley, A and Ferri, B. 2012. Journal of Research in Special Educational Needs, 12 (4), pp. 192-200 doi: 10.1111/j.1471-3802.2011.01230.x

[12] Goggin, G. M. and Newell, C.J. 2003. Digital Disability: The Social Construction of Disability in New Media. Lanham/Maryland, USA: Rowman \& Littlefield Publishers.
[13] Lazar, J. 2002. Integrating accessibility into the information systems curriculum. f. Comput. Inf. Syst. 3, 373-379.

[14] Máñez-Carvajal, C., Cervera-Mérida, J.F. \& Fernández-Piqueras, R. 2019. Web accessibility evaluation of top-ranking university Web sites in Spain, Chile and Mexico. Univ Access Inf Soc (2019). https://doi.org/10.1007/s10209-019-00702-w

[15] Matamala A., Orero P. (2019) Training Experts in Inclusive Practices for an Equity on Access to Culture in Europe. In: Halder S., Argyropoulos V. (eds) Inclusion, Equity and Access for Individuals with Disabilities. Palgrave Macmillan, Singapore. https://doi.org/10.1007/978-981-13-5962-0_13

[16] Matamala, A, and Orero, P. 2018. Standardising accessibility: transferring knowledge to society. Fournal of Audiovisual Translation 1 (1), 139-154.

[17] Oncins, E., Eugeni, C. and Bernabé, R., 2019. The Future of Mediators for Live Events: LTA project - Academic and Vocational Training. Cultus: the Intercultura Journal of Mediation and Communication, 12, pp.129-153.

[18] Orero, P. and Tor-Carroggio, I. 2018. User requirements when designing learning e-content: interaction for all. In Evangelos Kapros and Maria Koutsombogera (Eds.), Designing for the User Experience in Learning Systems, pp. 105-121. Cham: Springer.

[19] Perego, E. 2017. Audio Description: A Laboratory for the Development of a New Professional Profile. Rivista Internazionale di Tecnica della Traduzione/International Journal of Translation 19, 131-142.

[20] Pribeanu, C. 2019. Large-scale accessibility evaluation of Romanian municipal websites. IfUSI, 12(2), pp.83-98.

[21] Putnam, C., Dahman, M., Rose, E.J., Cheng, J., \& Bradford, G. 2016. Best Practices for Teaching Accessibility in University Classrooms: Cultivating Awareness, Understanding, and Appreciation for Diverse Users. ACM Trans. Access. Comput., $8,13: 1-13: 26$

[22] Seale, J. 2004. The Development of accessibility practices in e-learning: an exploration of communities of practice. ALT-J, Research in Learning Technology, 12(1) March 2004. Carfax Publishing: 51-63

[23] Taylor, C. 2017. Getting Our House in Order: Moving from Diversity to Inclusion. The American Archivist: Spring/Summer 2017, 80 (1), 19-29. 